EPiC Series in Engineering
Volume 3, 2018, Pages 2059-2066
HIC 2018. 13th International
Conference on Hydroinformatics

\title{
Simulation of scouring process downstream of a hydraulic structure and analysis of the effect of vegetation
}

\author{
Donatella Termini ${ }^{1}$ \\ ${ }^{1}$ Dipartimento di Ingegneria Civile, Ambientale, Aerospaziale, dei Materiali (DICAM) - \\ University of Palermo, Italy. Ph. 091/23896522; mobile: 3287274471 \\ donatella.termini@unipa.it
}

\begin{abstract}
In the present work a 1-D numerical model is applied to simulate the evolution of scouring process and the variation of the bed shear stress during transients. By the help of the model and by using experimental data collected in a straight flume, the paper also investigates how the presence of flexible vegetation on the bed could limit the evolution of the erosion process.
\end{abstract}

\section{Introduction}

The present paper focuses on transient bed profiles which are determined, under steady flow conditions, by a decrease of the upstream sediment transport rate. In particular, attention is paid to scouring process occurring downstream of the rigid basement of a hydraulic structure. The prediction of the evolution of scouring is difficult because of the development of three dimensional turbulent flow structures in the scour hole.

A new approach to simulate the erosion processes, the bed levels changes and the entity of sediment transported, taking into account the non-uniformity in sediment size and the interchange between the bed and the stream, was previously developed by Termini (2011a; 2012). The model allows the simulation of the variations of the longitudinal bed profile and the estimation of the material transported by the flow during transients. Furthermore, the model allows to account the spatial lag effect due to the fact that the alluvial stream is unable to immediately overcome the variation of sediment boundary conditions and an "adaptation distance" (spatial lag) is required to reach the equilibrium transport capacity. Considering this effect in scouring process is particularly important because of the feedback impact on the bed deformation description (Philips and Sutherland, 1989).

Based on this, the present paper is aimed at improving understanding both of the evolution of the erosion process and of how the introduction of flexible vegetation on the bed could affect it. This is motivated by the fact that submerged aquatic vegetation is abundant in many lowland river systems and exerts a strong influence on the functioning of the fluvial system. 
To this aim experimental runs were also performed in a straight channel constructed at the Hydraulic Laboratory of DICAM - University of Palermo (Italy) both in the absence (Termini and Sammartano, 2012) and in the presence (Termini, 2016) of vegetation on the bed. These experiments were carried out as a part of an experimental research program aiming to investigate sediment transport processes downstream of a hydraulic structure. In the absence of vegetation, an equation, which relates the bed shear stress and the sand volume eroded, was also determined (Termini and Sammartano, 2012).

\section{Materials and methods}

\subsection{Experimental apparatus}

The experiments were carried out by using the experimental apparatus shown in Figure 1. The rectangular flume is $11.2 \mathrm{~m}$ long and $0.4 \mathrm{~m}$ wide. In the first stretch, $2.6 \mathrm{~m}$ long, the bed is rigid while in the remaining part ( $8.5 \mathrm{~m}$ long) the bed is mobile (quartz sand with median sediment diameter $D_{50}$

$=0.86 \mathrm{~mm}$ and geometric standard deviation $\left.\sigma_{g}=1.61 \mathrm{~mm}\right)$. The longitudinal bed slope is equal to $0.4 \%$.

The evolution of the scouring process downstream of the rigid-bed reach was analyzed during a first experimental run (see also in Termini and Sammartano, 2012) carried out with water discharge $Q$ $=35 \mathrm{l} / \mathrm{s}$ (Froude number $\mathrm{Fr}=1.04$; Reynolds number $R e=4 \cdot 10^{5}$; roughness Reynolds number $R e^{*}=$ $52)$.

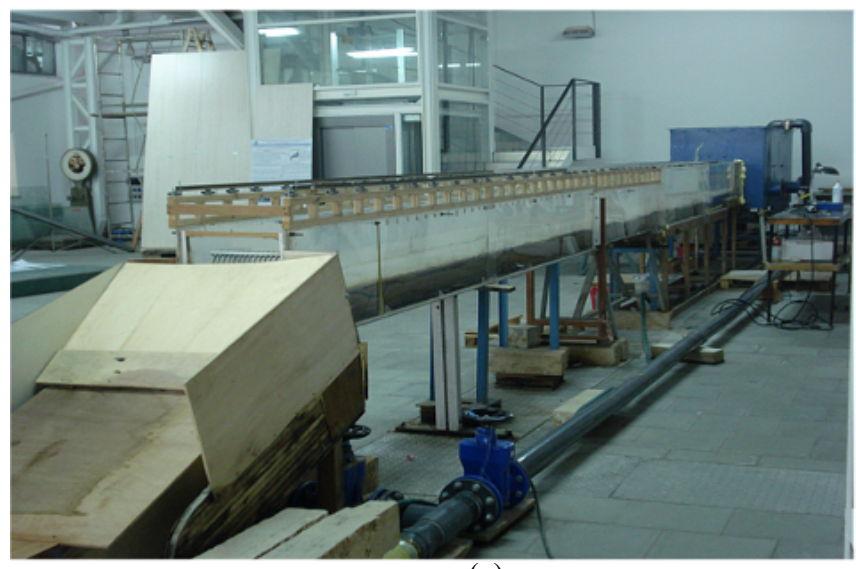

(a)

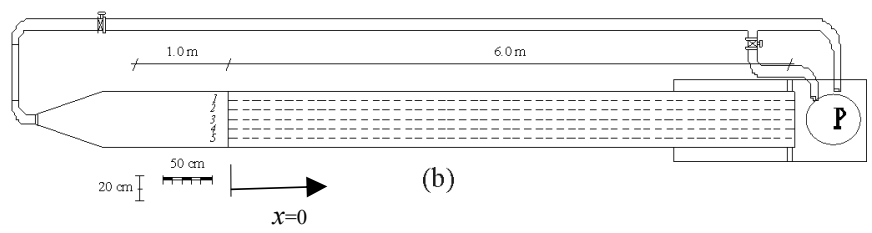

Figure 1: Experimental apparatus: a) overall picture; b) plane view 
During such an experimental run, it was observed that the scouring process develops downstream of the rigid bed: the length of the scour hole was around $30 \mathrm{~cm}$ and downstream of it a sand deposit extending for a length of almost $20 \mathrm{~cm}$ formed. Thus, the channel reach interested by scouring phenomenon had a total length, $L_{s}$, of $50 \mathrm{~cm}$. The maximum scour depth was obtained at a distance of $20 \mathrm{~cm}$ from the last section of the rigid-bed reach (see also details in Termini, 2011b). Flow velocity measurements were performed after that the scour hole was formed downstream of the rigid-bed and no significant variation of the scour profile was obtained. In particular, the longitudinal and vertical velocity components were measured using a two-dimensional laser anemometer - LDA2D by Dantec s.r.l.; the transversal component was measured through the ultrasonic anemometer DOP2000 by Signal Processing s.a. See details of measurement conditions in Termini and Sammartano (2012). Then, the channel reach $(1.60 \mathrm{~m}$ long) downstream of the rigid-bed was covered by real herbaceous (flexible) vegetation and a second run was carried out with the same flow discharge as that run conducted in the absence of vegetation. During this experimental run the vegetation was always submerged and the bent vegetation height $k_{v}$ was about equal to $2.6 \mathrm{~cm}$. The fractional plant area at the bed occupied by stems was equal to $13.5 \%$. During this run the instantaneous longitudinal, $u_{I}(t)$, transversal, $u_{2}(t)$, and vertical, $u_{3}(t)$, velocity components were measured by using the DOP2000 by Signal Processing s.a. (see in Termini, 2015; 2016).

\subsection{1-D numerical model}

The 1-D model includes two modules for the hydraulic and the sediment routing, respectively. The governing equations are synthetically described below; more details of the numerical model can be found in previous works [Termini, 2011a, b; 2012]:

- Equations for hydraulic routing

$$
\begin{aligned}
& \frac{\partial h}{\partial t}+\frac{\partial q}{\partial x}=0 \\
& \frac{\partial q}{\partial t}+\frac{\partial}{\partial x}\left(\frac{q^{2}}{h}\right)+g h \frac{\partial h}{\partial x}+g h \frac{\partial z_{b}}{\partial x}+g \frac{n^{2} q^{2}}{h^{7 / 3}}=0
\end{aligned}
$$

- Equations for sediment routing

$$
\begin{aligned}
& \frac{\partial q_{s b, k}}{\partial x}+\varphi_{s, k}=-(1-\lambda) F_{k} \frac{\partial\left(z_{b}+\delta_{a}\right)}{\partial t} \\
& \frac{\partial\left(C_{k} h\right)}{\partial t}+\frac{\partial\left(C_{k} q\right)}{\partial x}=\frac{\partial}{\partial x}\left(h K_{x} \frac{\partial C_{k}}{\partial x}\right)+\varphi_{s, k} \\
& \frac{\partial q_{s b, k}}{\partial x}=\phi_{k}\left(q_{s b, k}^{*}-q_{s b, k}\right)+\alpha_{k} \frac{\partial q_{s b, k}^{*}}{\partial x}
\end{aligned}
$$




$$
\begin{aligned}
& \varphi_{s, k}=\left(E_{k}-D_{k}\right) \\
& \sum_{k=1}^{N} F_{k}=
\end{aligned}
$$

with $h=$ water depth, $q=$ flow rate per unit width, $z_{b}=$ bed level, $t=$ time, $x=$ distance in flow direction, $g=$ gravitational acceleration, $n=$ Manning coefficient that is related to the dimensionless Chèzy resistance factor, $c$, by: $n=\frac{h^{1 / 6}}{c \sqrt{g}}, \delta_{a}=$ thickness of surface active layer, $\lambda$ $=$ sediment porosity, $q_{s b, k}$ and $\mathrm{q}_{\mathrm{sb}, \mathrm{k}}^{*}=$ the actual and the equilibrium specific volumetric bed-load sediment transport rate for size class $k$, respectively, $F_{k}=$ fractional representation of size class $d_{k}, C_{k}=$ vertically averaged concentration of suspended sediment of size class $k, K_{x}=$ longitudinal dispersion coefficient for suspended sediment, $D_{k}$ and $E_{k}=$ sediment deposition and resuspension rates respectively

Eq. 1 and Eq. 2 represent, respectively, the continuity equation and the momentum equation for water, Eq. 3 is the conservation of sediments of $k$-th size class transported as bed load; Eq. 4 indicates the conservation of sediments of $k$-th size class transported in suspension; Eq. 5 indicates the spatial delay of bed load transport rate; Eq. 6 indicates the exchange between bed load and suspended load for each $k$-th size class; finally, Eq. 7 indicates the conservation of the total grain size distribution.

The term $\phi_{\mathrm{k}}$ in Eq. 5 represents the so-called adaptation coefficient which takes into account the spatial lag effect. This effect is especially evident within the scour hole.

Thus, the profiles of the scour hole, measured at different times as described in the previous section, have been also used to evaluate the bed load transport within the channel reach downstream of the rigid bed; according to Termini $(2011 \mathrm{~b}), \phi_{\mathrm{k}}$ has been estimated by considering the time evolution of sediment transport rate along this channel reach. It has been observed that, the local difference at time $t$ between the non-equilibrium and the equilibrium bed load transport, $\Delta q_{s b},{ }_{x, t}$, decreases until that it assumes an almost null value as the equilibrium condition is reached. Furthermore, it has been also observed that in the initial stage of the phenomenon evolution, $\Delta q_{s b},_{x, t}$ strongly increases as the distance $x$ increases; approaching to the equilibrium, the variation of $\Delta q_{s b},{ }_{x, t}$ with the distance $x$ is very small.

Based on the aforementioned, according to Termini (2011b), Eq. (5) has been rewritten in the following form:

$$
\begin{aligned}
& \frac{\partial q_{s b, k}}{\partial x}=\phi_{k}\left(q_{s b, k}^{*}-q_{s b, k}\right)+\frac{\partial q_{s b}^{*}}{\partial x} \\
& \text { with } \quad \phi_{k}=\frac{\left.a_{t}\right|_{x}}{\left(q_{s b}\right)_{x=L_{s}}} ;\left.\quad a_{t}\right|_{x}=2 D_{50, x} e^{-t\left(0.0002 D_{50, x}\right)}
\end{aligned}
$$


where $L_{s}$ is the scour length and $D_{50, x}$ is the local median sediment diameter.

The sediment routing module includes also closure equations for variables $D_{k}, E_{k}, K_{x,} \lambda, q_{s b, k}^{*}$, c, as explained in previous works (Termini, 2011b; 2012)..

\section{Results}

First, the collected data have been used to investigate how the pattern of the bed shear stress along the scour hole obtained in absence of vegetation could be simulated by the model. Then, the experimental data have been used to investigate how the presence of flexible vegetation could affect the sediment transport process.

The Reynolds shear stress is a crucial variable for understanding the dynamics of sediment transport by fluids. Thus, the turbulent fluctuation components have been determined by using the measured time series of flow velocity components collected both in the absence and in the presence of vegetation on the bed; the values of Reynolds shear stress on longitudinal planes have been evaluated as $\overline{u_{1}^{\prime}(t) w_{3}^{\prime}(t)}$. In accordance with other authors (among others Bennett and Best, 1995; Graf, 1996), the bed shear stress, $\tau_{b}$, has been estimated by using the vertical profile of the Reynolds stress projected to the zero bed height.

In the absence of vegetation, the application of the regression analysis to obtained values of $\tau_{b}$ yielded the following expression (see also in Termini and Sammartano, 2012):

$$
\hat{\tau}=[(a Y+b) \ln \hat{W}]+c \sin (d Y+e)+1.0285
$$

where $\hat{\tau}=\tau_{b} / \tau_{a v}\left(\tau_{a v}=\right.$ the average bed shear stress in each section) and $\hat{W}=W / W_{t o t}(W=$ volume of sand eroded at generic section and $W_{t o t}=$ total volume of sand eroded along the channel reach interested by scouring; $Y$ indicates the transversal axis). For the considered case, the coefficients assume the following values: $a=0.02, b=-0.35, c=1.148, d=0.1995, e=0.4442$.

The evolution of scouring process has been also simulated by applying the numerical model (Termini, 2011a, b) and the values of $\hat{\tau}$ have been determined by the model. In Figure 2 the experimental values of $\hat{\tau}$ are compared with the computed ones. 


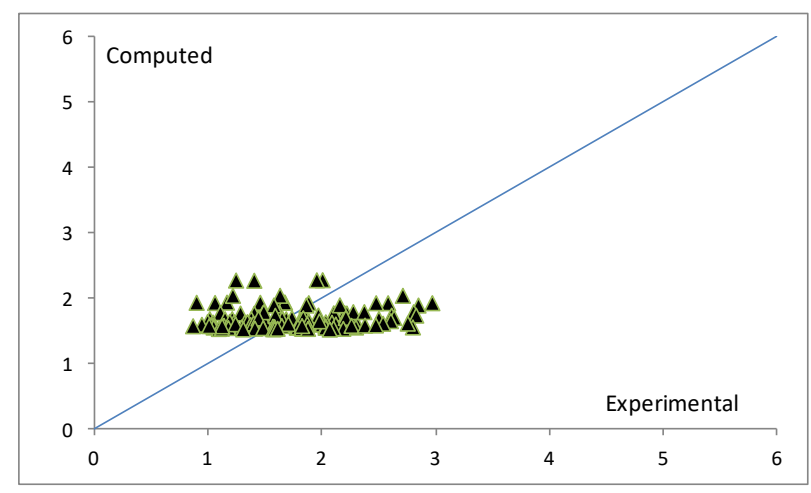

Figure 2: Comparison between experimental and computed $\hat{\tau}$

Figure 2 shows that the points concentrate around the bisector line (although model tends to underestimate the bed shear stress). In any case, Figure 2 confirms that Equation 10 allows the estimation of the variation of the bed shear stress during transients. This means that the distribution of the bed shear stress can be estimated as a function of total volume of sand eroded along the channel reach interested by scouring.

Then, in order to investigate how the presence of flexible vegetation could affect the evolution of the scouring process, the values of the bed shear stress estimated in the absence of vegetation have been compared with those obtained in the presence of vegetation downstream of the rigid bed.

Figure 3 reports the comparison between the values of the bed shear stress, $\tau_{b}$, estimated along the channel reach downstream of the initial section (that is $50 \mathrm{~cm}$ long), both in the absence and in presence of vegetation. As Figure 3 shows, in the absence of vegetation the bed shear stress assumes the higher positive values in correspondence of the deepest region of the scour (see also in Termini and Sammartano, 2012). In the presence of vegetation, the bed shear stress assumes very low values; in particular, these values of $\tau_{b}$ are generally lower than those obtained in the absence of vegetation. 


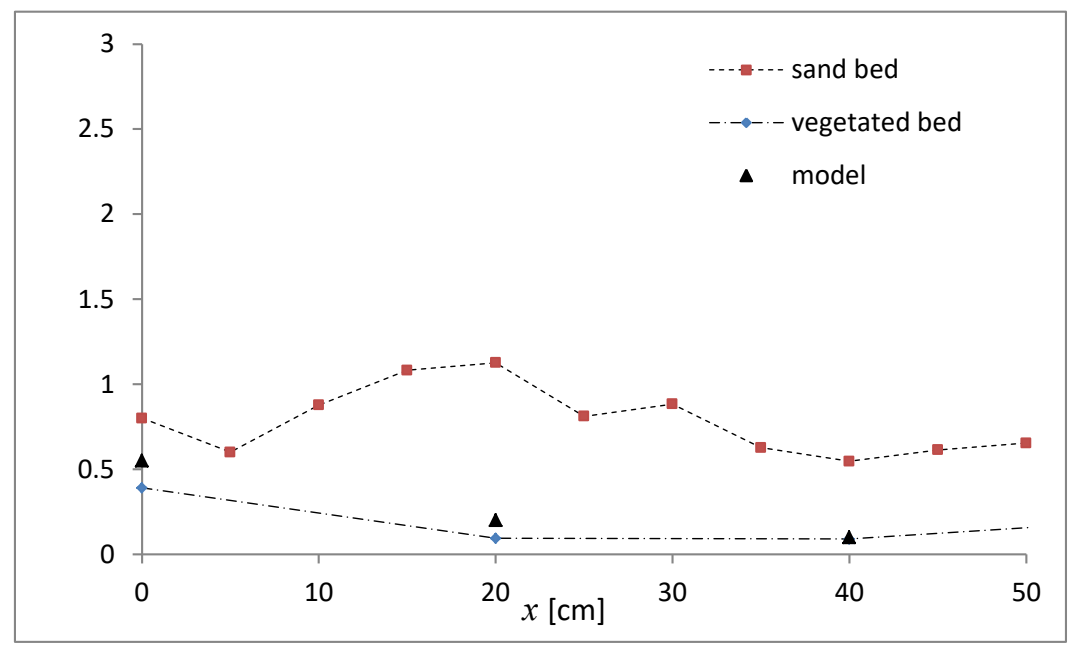

Figure 3: Comparison between the values bed shear stress, $\tau_{b}$, estimated in the absence of vegetation with those measured and computed in the presence of vegetation

The values of the bed shear stress in the presence of vegetation have been also estimated by applying the model. In this case, the Manning's coefficient $n$ in Eq. (2) has been obtained by applying the Carollo et al.'s (2005) expression in estimating the flow resistance with submerged vegetation:

$$
\mathrm{c}=\frac{u_{m}}{u_{*}}=A_{o}\left(\frac{h}{k_{v}}\right)^{a}\left(\frac{u_{*} k_{v}}{v}\right)^{b}\left(\frac{H_{v}}{k_{v}}\right)^{c}
$$

where $H_{v}=$ vegetation height, $A_{o}=$ parameter that can be estimated as a function of the vegetation concentration, $a, b, c=$ coefficients whose value depends on the stems concentration. The value of the parameter $A_{o}$ can be estimated by using the graph reported in Carollo et al. [10]; the values of the coefficients $a, b, c$ can be determined by using the experimental data.

As Figure 3 shows the computed values of the bed shear stress are in good agreement with the measured ones in the presence of vegetation.

\section{Discussion and conclusion}

The present paper focuses on the simulation of the sediment transport processes during transients both in the absence and in the presence of flexible vegetation. A 1D numerical model previously developed has been applied to estimate the distribution of the bed shear stress along the channel reach downstream of a rigid bed. In the absence of vegetation, the comparison between the computed values of the bed shear stress and those determined by using experimental data has highlighted that the variation in time of the bed shear stress can be estimated as a function of total volume of sand eroded along the channel reach interested by scouring, according with previous results obtained by Termini 
and Sammartano (2012). Then, it has been verified that the pattern of bed shear stress, $\tau_{b}$, obtained in the scour hole in the absence of vegetation is different to that obtained in the presence of flexible vegetation. In particular, results show that once the vegetation is introduced, the erosive action of the flow is strongly attenuated and the scouring process does not develop downstream of the structure.

\section{References}

Bennett, S.J. and Best, J.L. ,1995. Mean flow and turbulence structure over fixed, two-dimensional dunes: implications for sediment transport and bedform stability. Sedimentology, 42, 491-514.

Carollo, G., Ferro, V., Termini, D. 2005. Flow Resistance Law in Channels with Flexible Submerged Vegetation. Journal Hydraulic Engineering , 131(7), 554-564

Graf, W.H., 1996. Bed-load transport in unsteady open channel flow. XXV Convegno di Idraulica e Costruzioni Idrauliche. Torino (Italy), 1-24.

Phillips, B.C., Sutherland, A.J., 1989. Spatial lag effects in bed load sediment transport. Journal of Hydraulic Research, 27(1): 115-133.

Termini, D., 2011a. 1- D numerical simulation of sediment transport in alluvial channel beds: study cases. European Journal of Environmental and Civil Engineering- EJECE 15(2), DOI:10.1080/19648189.2011.9693322; pp. 269-292.

Termini, D., 2011b. Bed scouring downstream of hydraulic structures under steady flow conditions: Experimental analysis of space and time scales and implications for mathematical modeling. CATENA 84 - Elsevier B.V. doi:10.1016/j.catena.2010.10.008, pp. 125-135

Termini D., 2012. Numerical simulation of non-equilibrium sediment transport in a flume - Erosion and Sediments Yields in the Changing Environment (IAHS Publ.356) -ISSN 0144-7815.

Termini D. and Sammartano V., 2012. MORPHODYNAMIC PROCESSES DOWNSTREAM OF MAN-MADE STRUCTURAL INTERVENTIONS: experimental investigation of the role of turbulent flow structures in the prediction of scour downstream of a rigid bed. Physics and Chemistry of the Earth (2012) - Elsevier B.V. doi.org/10.1016/j.pce.2011.12. vol. 49 (2012). pp. $18-31$.

Termini D. 2015. Reduction of scouring downstream of a rigid bed by means of a vegetated carpet: experimental investigation in a laboratory flume. Environmental Fluid Mechanics. 2016. DOI 10.1007/s10652-016-9467-y

Termini D., 2016. Reduction of scouring downstream of a rigid bed by means of a vegetated carpet: experimental investigation in a laboratory flume. Environmental Fluid Mechanics. 2016. Volume 16 Issue 6, Pages: 1111-1127. 